\title{
Analysis and Design of Voltage Control of Static Condenser
}

\author{
K.R. Padiyar \\ A.M.Kulkarni \\ Department of Electrical Engineering \\ Indian Institute of Science \\ Bangalore, India 560012 \\ 91-80-3341566 krpyar@ee.iisc.ernet.in
}

\begin{abstract}
The STATic CONdenser (STATCON) is a shunt connected voltage source converter using self commutating device like GTO $\mathrm{s}$. The principle of working is similar to that of a synchronous condenser. This paper is concerned with the application of the STATCON for the reactive power compensation of a long transmission line by regulating the voltage at its midpoint. The design of the voltage controller and the analysis of its dynamic behaviour using eigenvalue analysis and digital simulation is presented. An important observation is that the plant transfer function is generally of the nonminimum phase type. This precludes the use of large gains in a PI controller as there is a risk of instability of an oscillatory mode of frequency between $200-300 \mathrm{rad} / \mathrm{s}$. Eigenvalue analysis using linearized model was carried out to design a compensator in cascade with an integral controller to overcome this problem.
\end{abstract}

\section{INTRODUCTION}

The concept of FACTS [1] (Flexible AC Transmission Systems) envisages the use of solid state controllers to achieve flexibilty of system operation with fast and reliable control. Reactive power controllers like SVCs using thyristors have already been operated sucessfully .Fast control over the reactive power can allow (secure) loading of transmission lines nearer their thermal limits, greater control over the power flow, regulate voltage and improve system damping. Static Condenser (STATCON) $[2,3,4,5]$ is a second generation FACTS device based on voltage source converter using self commutating devices like GTOs and could be used for shunt reactive power compensation. The converter is connected to the system bus through a small reactance which is the leakage reactance of the coupling transformer (Fig.1). The reactive power drawn or supplied by the STATCON can be varied by varying the magnitude of the converter output voltages. Ideally, the output voltages of the converter are in phase with the corresponding bus voltages. However a small phase difference exists in steady state (which depends on the reactive power output) so that active power may be drawn from the lines to compensate for the losses. The current on the DC side is mainly a ripple of magnitude much smaller than the ac line currents. As no real power exchange in the steady state is involved, the DC voltage can be maintained by an energy storage capacitor. The output voltage contains harmonics and therefore higher pulse numbers are usually used.

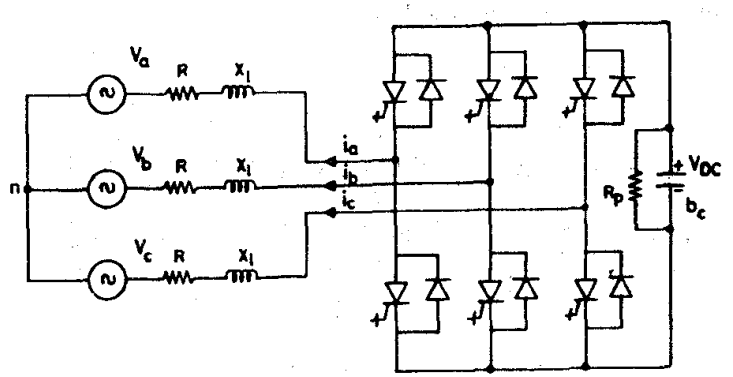

Fig.1 Six Pulse STATCON

It is advantageous to provide reactive power compensation in long radial transmission lines. This is usually done at the midpoint of the transmission line in order to maximize power transfer capability as well as maintain voltage within limits under stressed or underloaded conditions. While fixed or mechanically switched capacitors/ reactors can provide the 
required compensation in the steady state, fast reactive power control using thyristor based Static VAR Compensators (SVC) or the STATCON can vastly increase the transient stability limit of power transfer. Besides, by modulation of reactive power it is possible to damp oscillations. The application of the STATCON used for the reactive power compensation of a long transmission line by voltage control at its midpoint is discussed in this paper. Digital Simulation and eigenvalue analysis are used to design a fast voltage controller.

\section{SYSTEM MODEL}

Since the number of differential equations required to describe the power system is very large it is necessary to use a simplified model wherever possible. In transient stability studies generator stator and network transients are neglected because rotor swings are comparatively "slow". In fact in these studies , the SVC controller dynamics can be neglected and the SVC can be modelled by the steady state characteristics. In turn, when studying the fast dynamics associated with the SVC or STATCON controller the network transients cannot be neglected while the slowly changing dynamic variables associated with the generator rotor can be frozen at their pre-disturbance values.

\subsection{Network Model}

The SMIB system to be studied is shown in Fig.2. The generator is represented by a voltage source behind a transient reactance. The network is represented by two pi equivalents.

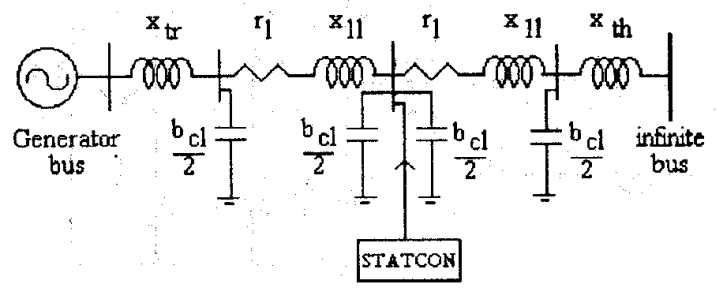

Fig.2 System under study

It is convenient to formulate the network differential equations in the D-Q reference frame. They can be written as

$$
\underline{\dot{x}_{N}^{D Q}}=\left[A_{N}\right] \underline{x_{N}^{D Q}}+\left[B_{N S}\right] \underline{u_{N S}^{D Q}}+\left[C_{N}\right] \underline{v_{G}}
$$

where $x_{N}^{D Q}$ are the state variables associated with the network elements.
$\underline{u_{N S}}=\left[\begin{array}{ll}i_{D S} & i_{Q S}\end{array}\right]^{T}$ are the STÁTCON injected currents in the $D-Q$ reference frame .

$v_{G}$ is the vector of generator and infinite bus voltages.

\subsection{Mathematical Model of STATCON}

The exact differential equations for the STATCON use switching functions which are difficult to handle for varying firing angle. However if one neglects the harmonics the line currents and ac voltages can be transformed to the Kron's (synchronously rotating) frame of reference. The resulting equations in the D$Q$ variables are time invariant and are given by

$$
\begin{aligned}
& {\left[\begin{array}{c}
\frac{d i_{Q}}{d t} \\
\frac{d i_{Q}}{d t} \\
\frac{d v_{D C}}{d t}
\end{array}\right]=\left[\begin{array}{cc}
\frac{-w_{Q}}{w_{1}} & 0 \\
0 & \frac{-w_{Q}}{x_{l}} \\
0 & 0
\end{array}\right]\left[\begin{array}{l}
v_{D S} \\
v_{Q S}
\end{array}\right]+} \\
& {\left[\begin{array}{ccc}
-\frac{R \omega_{\alpha}}{x_{I}} & -\omega & \frac{\omega_{0} k \operatorname{Sin}(\alpha+\theta)}{x_{l}} \\
\omega & -\frac{R \omega_{0}}{x_{l}} & \frac{\omega_{0} k C C_{l}(\alpha+\theta)}{x_{l}} \\
-\frac{\omega_{0} k \operatorname{Sin}(\alpha+\theta)}{b_{c}} & -\frac{\omega_{0} k C(\alpha+\theta)}{b_{c}} & -\frac{\omega_{0}}{b_{c} R_{p}}
\end{array}\right]\left[\begin{array}{c}
i_{D S} \\
i_{Q S} \\
v v_{D C}
\end{array}\right]}
\end{aligned}
$$

where $k=\frac{2 \sqrt{6}}{\pi}$ for a 12-pulse STATCON $\bar{V}_{S}=V_{S} \angle \theta=v_{Q S}+j v_{D S}=$ STATCON terminal voltage, $\alpha=$ firing angle.

Note that $\alpha$ is the angle by which the converter output voltage leads the bus voltage. It can be shown that a positive value of $\alpha$ implies that the STATCON is in the inductive region (consumes reactive power) while a negative value implies that it is in the capacitive region. The above equation can be written as

$$
\underline{\dot{x}_{S}^{D Q}}=\left[A_{S}(\alpha)\right] \underline{x_{S}^{D Q}}+\left[B_{S N}\right] \underline{u_{S N}^{D Q}}
$$

where $\frac{x_{S}^{D Q}}{v^{2}}=\left[\begin{array}{lll}i_{D S} & i_{Q S} & v_{D C}\end{array}\right]^{T}$

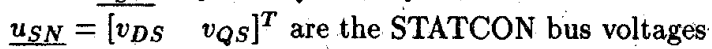
in the $D-Q$ reference frame.

Linearizing about an operating point we get

$$
\underline{\Delta \dot{x}_{S}^{D Q}}=\left[A_{S}^{0}\right] \underline{\Delta x_{S}^{D Q}}+\left[B_{S N}\right] \underline{\Delta u_{S N}^{D Q}}+\left[B_{\alpha}^{0}\right] \Delta \alpha
$$

\section{CONTROLLER STRUCTURE}

As pointed out in the previous section, fast reactive power control (RPC) can improve transient stability. The standard control strategy for RPC is to regulate the voltage. The ability of the STATCON to regulate voltage under widely varying operating conditions is dependent on its rating. Voltage reference for the voltage regulator itself may be adjusted so that the system satisies certain steady state constraints. The STATCON can be used in conjunction with fixed or mechanical switched compensation (which will provide most of the reactive power required in the steady state) so as to reduce the required ratings and steady. 
state losses of the STATCON and to make available maximum controllable compensation during faults. The control characteristic of the STATCON and a FC-TCR (Fixed Capacitor - Thyristor Controlled Reactor) type SVC is shown in Fig.3 . It is apparent that at the limits the STATCON supplies reactive power proportional to the voltage whereas the SVC has fixed susceptance characteristics when it hits its limits.

SVC is a variable impedance type RPC. The susceptance of the TCR depends on the firing angle of the thristors alone: The STATCON varies the injected (reactive) current by varying the magnitude of the converter output voltages. The reactive current is not only dependent on the firing angle of the devices, but on the bus voltage as well (which is a complicated function of the injected reactive current and system parameters).

The structure of an SVC controller is shown in Fig.4a. Since the susceptance as a (nonlinear) function of firing angle is known the controller has two stages. The firing angle can be derived directly from $B_{\text {ref }}$ (no feedback control of $B_{r e f}$ is necessary), while $B_{r e f}$ is set by the outer voltage controller.

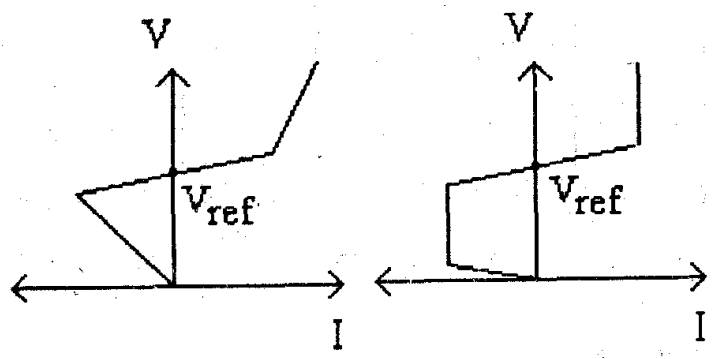

$\begin{array}{ll}\text { (a) SVC } & \text { (b)STATCON } \\ \text { Fig.3 Control characteristics }\end{array}$

For the STATCON an "inner loop" for reactive current control (Fig.4b) is desirable since $i_{R}$ is not a function of firing angle alone. The outer controller in both cases is generally of the proportional (P) or the proportional-integral(PI) type with high values of gain for tight control of voltage. There is an additional advantage that reactive current limits can be incorporated into the controller itself.

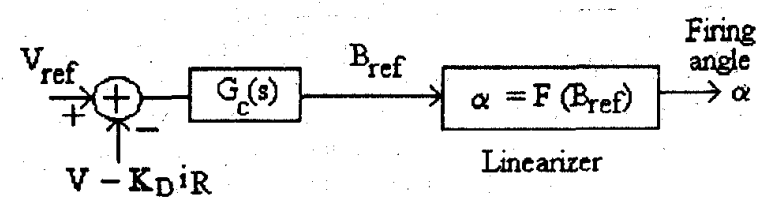

Fig.4(a) SVC Contröller structure

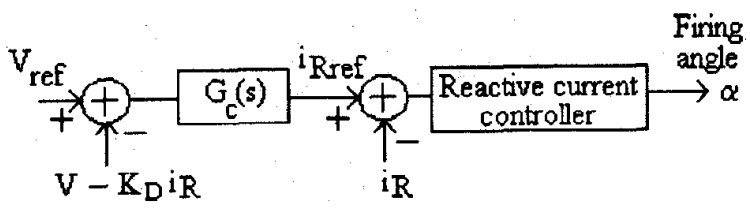

Fig.4(b) STATCON Controller structrure

\section{REACTIVE CURRENT CONTROLLER}

Reactive current is defined as

$$
i_{R}=\frac{i_{D S} v_{Q S}-i_{Q S} v_{D S}}{V_{S}}
$$

By this convention, positive $i_{R}$ implies the STATCON is in the inductive region while negative $i_{R}$ implies it is in the capacitive region.

Regulation of the reactive current using output feedback and PI controller was investigated. In the design of the reactive current controller bus voltage is assumed to be constant. The linearized mathematical model of the STATCON (Eq.3) is used. The location of the poles of the plant transfer function $\left(\frac{\Delta i_{\text {Rref }}}{\Delta \alpha}\right)$ is independent of the operating point. The zero locations are such that a pair of (closed loop) poles are driven to towards the imaginary axis with increasing gain (Fig.5) when the STATCON operates in the inductive region. Schauder and Mehta[6] have pointed out that this system is not amenable to classical feedback control. They have proposed a nonlinear feedback in addition to the PI controller (Fig.6) so as to improve the damping in the inductive region. This controller shows a good response to a step change in reference (Fig.7).

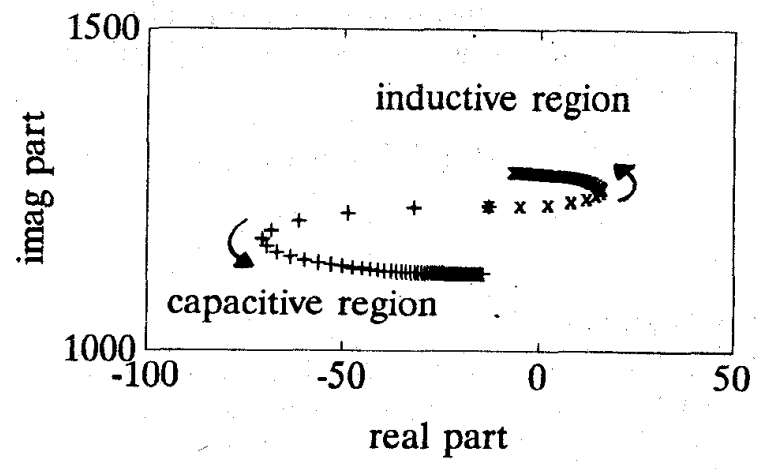

Fig.5 Eigenvalue locus for increasing gain (PI controller) 


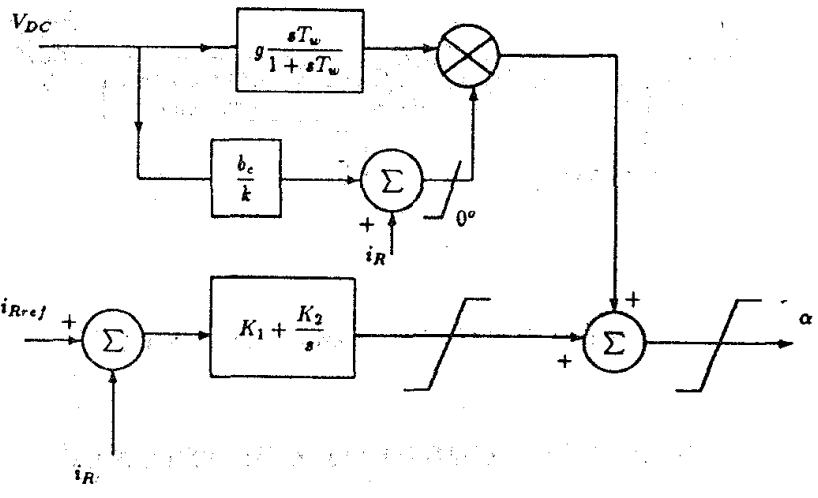

Fig.6 Nonlinear reactive current controller

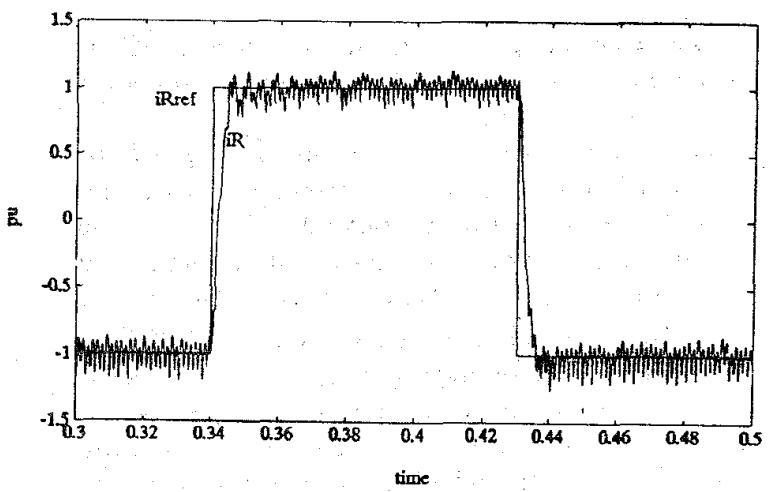

Fig.7 Response for step change in $i_{R r e f}$

\section{PLANT TRANSEER FUNCTION}

The transfer function of interest for voltage control and the controller structure described previously is $\frac{\Delta V}{\Delta i_{\text {rref }}}$. The state equations of the combined system can be written as

$$
\underline{\Delta \dot{x}^{D Q}}=\left[A^{0}\right] \underline{\Delta x^{D Q}}+\left[B^{0}\right] \underline{\Delta i_{R r e f}}
$$

The output is the magnitude of the STATCON bus voltage

$$
\Delta V_{S}=\frac{v_{Q S}^{0}}{V_{S}^{0}} \Delta v_{Q S}+\frac{v_{D S}^{0}}{V_{S}^{0}} \Delta v_{D S}
$$

The nature of the plant transfer function was investigated for various operating conditions. Case \#1 and \#2 (see Table I) represent the situation when a single circuit line is transmitting power to the infinite bus. The line is stressed and therefore capacitive compensation is required at the midpoint. This can be achieved in two ways; Either STATCON alone is used (Case \#1) or it is used in conjunction with a Fixed Capacitor (Case \#2). Similarly Case \#3 and Case \#4 represent inductive compensation when a double circuit line is used." Table II shows the operating conditions of the STATCON for the abovementioned cases and the critical pole-zero locations (reactive current controller of PI type).

Table I: Operating Conditions (network)

$$
P_{g}=0.8 p t
$$

\begin{tabular}{|c|c|c|c|c|}
\hline Table & Critic & \multicolumn{2}{|c|}{ Pole-Zero } & Locations \\
\hline & $Q_{F I X E D}$ & $Q_{S}$ & Zeros & Poles \\
\hline Case \#1 & 0.0 & 0.22 & \begin{tabular}{|l|}
447.3 \\
-448.3
\end{tabular} & $-47.1 \pm j 223.2$ \\
\hline Case \#2 & 0.22 & 0.0 & $\begin{array}{r}571.2 \\
-549.3\end{array}$ & $-37.3 \pm j 207.8$ \\
\hline Case \#3 & 0.0 & -0.22 & $\begin{array}{r}2196.1 \\
-2191.8\end{array}$ & $-62.0 \pm j 271.1$ \\
\hline Case \#4 & -0.22 & 0.0 & $\begin{array}{r}641.1 \\
-670.0 \\
\end{array}$ & $-58.2 \pm \mathrm{j} 264.2$ \\
\hline
\end{tabular}

\begin{tabular}{|l|c|c|c|}
\hline & & $V_{g}$ & $\bar{V}_{S}$ \\
\hline $\begin{array}{l}\text { Case \#1 } \\
\text { Case \#2 }\end{array}$ & $\begin{array}{c}\text { Single } \\
\text { line }\end{array}$ & $1.05 \angle 65$ & $1.023 \angle 32.6$ \\
\hline $\begin{array}{l}\text { Case \#3 } \\
\text { Case \#4 }\end{array}$ & $\begin{array}{c}\text { Double } \\
\text { line. }\end{array}$ & $1.05 \angle 37.5$ & $1.0284 \angle 19$ \\
\hline
\end{tabular}

\section{Remarks}

1 There exists a zero on the right half of the complex plane (on the positive real axis), ie., the plant is of nonminimum phase type. This is true for all the cases shown. The (zero frequency) gain of the compensator transfer function consequently has to be negative in order that steady state be reached. This is consistent with the fact that for a drop in voltage (positive error) a negative change in $i_{R}$ is required while an increase requires a positive charge in $i_{R}$.

2 As an example, for Case \#1 the plant transfer function is

$$
\frac{\Delta V(s)}{\Delta I_{\text {Rref }}(s)}=\frac{(s-447.3)(s+488.2)}{\left(s^{2}+94.2 s+52171\right)} T_{i}(s)
$$

where the poles and zeros of $T_{i}(s)$ have negligible effect on the controller. It can be inferred from classical root locus techniques that a pair of-complex poles will move towards the right half plane for inreasing gains with a PI type controller resulting in an unstable ascillatory mode of frequency around $200-250 \mathrm{rad} / \mathrm{s}$. This 
is shown in Fig.8. Fig.9 shows this instability in $i_{R}$ as obtained from digital simulation using TUTSIM[8]. Lower gains are not admissible as it renders the response unacceptably slow.

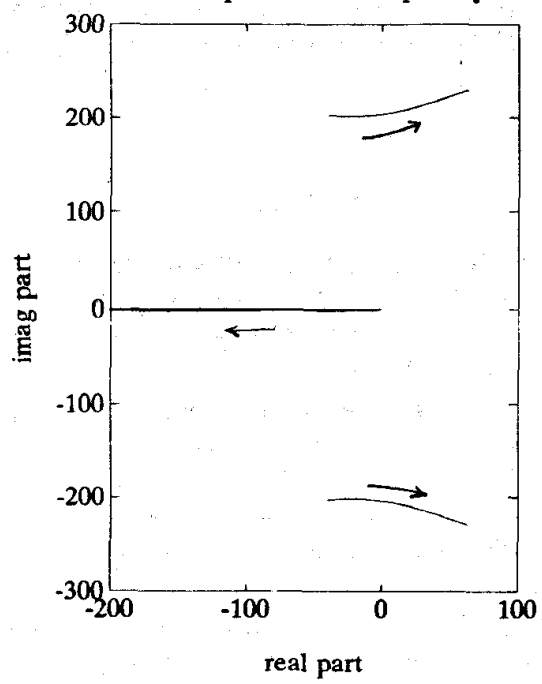

Fig. 8 Root loci for increasing gain with integral voltage controller ( $k_{i}: 0$ to 400$)$ Reactive current controller is of PI type.

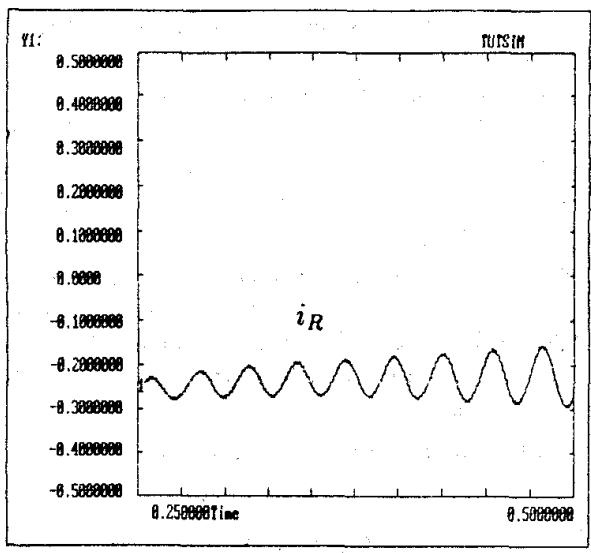

Fig.9 Instability with $k_{i}=25$

\section{CONTROLLER DESIGN}

It is apparent that an output feedback configuration with a P, PI or I controller alone is not feasible. A compensator in cascade with a PI controller to overcome this problem is conceptually the most simple solution and easiest to implement. However the following points are to be borne in mind,

1 While a pair of poles will eventually migrate towards the RHS of the complex plane for large gains, the compensator has to ensure that there is a range of values of gains which allow for a fast response and maintain stability.

2 Cancelling the open loop poles associated with the oscillatory mode exactly with zeros of the compensator is not possible; however the movement of this pole towards the imaginary axis can be inhibited by placing the compensator zeros close to these poles and ensuring that the angle of departure is towards the LHS of the complex plane by choosing the poles of the compensator appropriately.

Using $G_{c}^{\prime}(s)=\frac{s^{2}+a_{1} s+a_{2}}{s^{2}+b_{1} s+b_{2}}$

with two poles and two zeros in cascade with the integral controller i.e.

$G_{c}(s)=-\frac{k_{i}}{s} G_{c}^{\prime}(s)$

it is possible to cancel the effect of the critical poles. The poles of the compensator are placed further to the left of the imaginary axis than the zeros. Note that the compensator can also be placed in the feedback path.

The compensator can be considered as a notch controller which attenuates the oscillatory mode (see frequency response in Fig.10). The root loci of the system is shown in Fig. 11 brings out the improvement. Fig.12 shows the simulated response for step change in voltage reference.
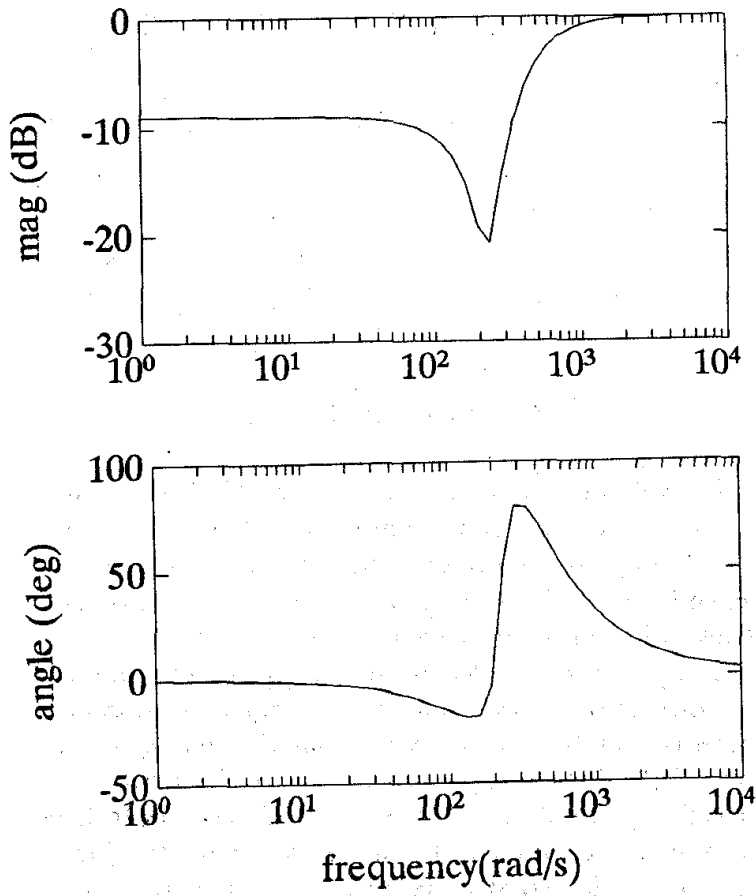

Fig.10 Frequency response of controller 


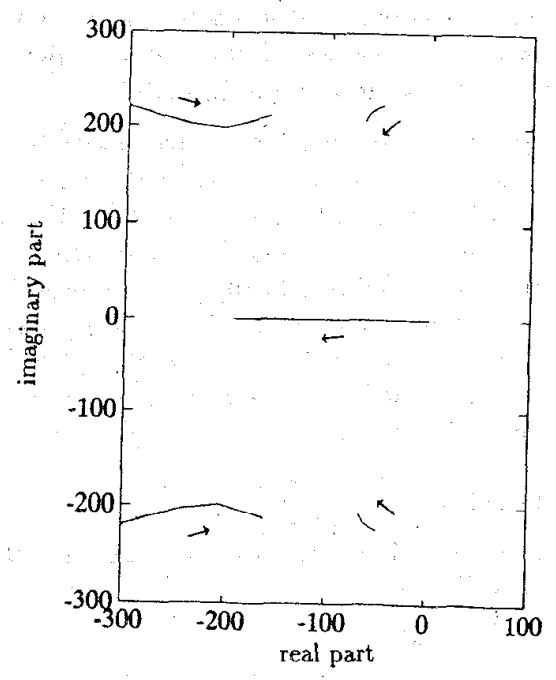

Fig.11 Root loci with compensator $\left(k_{i}: 0\right.$ to 400$)$

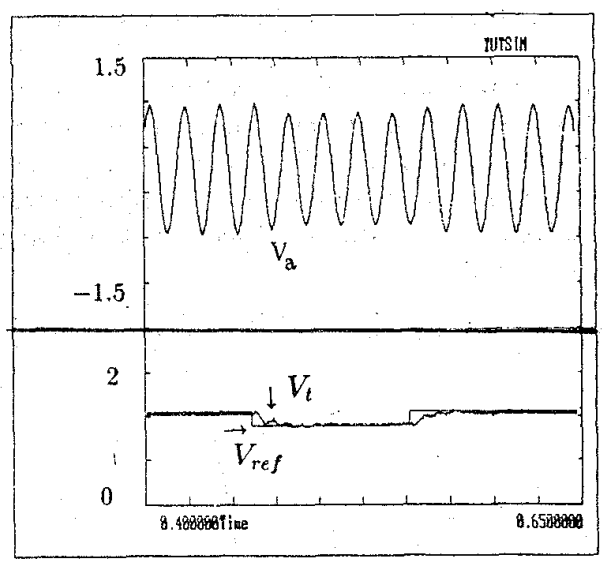

Fig.12 Response to step change in $V_{r e f}$

\section{CONCLUSIONS}

The preferable structure of the STATCON controller is the use of output feedback for voltage regulation; the voltage regulator sets the reactive current reference for the (closed loop) reactive current controller. Network transients need to be considered while designing the controller unlike in transient stability studies of the power system. An important observation is that the plant transfer function has a zero in the RHS of the complex plane, which destabilizes an oscillatory mode if $\mathrm{P}, \mathrm{PI}$ or integral type controllers are used. A compensator in cascade with the intregral controller to attenuate this mode is necessary so that high gains may be used for fast response.

\section{Acknowledgment}

The financial support received from the Department of Science and Technology, Government of India under the project titled, "Flexible AC Transmission Systems (FACTS) Controllers" is gratefully acknowledged.

\section{References}

1 N.G.Hingorani, "FACTS- Flexible AC Transmission Systems",Conf. Publication no. 345, IEE Int. Conf. on $A C$ and DC Power Transmission, London, Sept.1991, pp.1-7.

2 Y.Sumi et al, "New Static VAR Control using Force Commutated inverters", IEEE Trans. PAS-100, no.9,Sept. 1981, pp 4216-4224

3 L.Gyugyi, "Reactive Power Generation and Control by Thyristor Circuits",IEEE Trans., IA-15, no.5 ,Sept/Oct 1979, pp 521-532.

4 C.W.Edwards et al, "Advanced Static Var Generator employing GTO Thyristors". ,IEEE Trans. Power Delivery, Vol.3, No.4, Oct. 1988, pp. 16221627

5 C.Schauder et al, "Development of a $\pm 100 \mathrm{MVAR}$ Static Condenser for voltage control of Transmission Systems" Paper 94 SM 479-6 PWRD ,IEEE/PES 1994 Summer Meeting, San Francisco, CA, July 1994

6 C.Schauder and H. Mehta, "Vector Analysis and Control of Advanced Static Var Compensators", Publication no. 345,IEE Int. Conf. on $A C$ and DC Power Transmission, London, Sept.1991, pp. 266-272.

7 K.R.Padiyar and A.M.Kulkarni, "Transient Simulation of Static Condenser ",New Concepts in EHV/UHV $A C$ and DC Transmission", Ninth National Convention of Electrical Engineers, Nov. 1993, Bangalore, India

8 TUTSIM on IBM PC ,Users Manual Ver. 6.55

\section{APPENDIX}

Network data

Base : $1000 \mathrm{MVA}, 400 \mathrm{kV}, 50 \mathrm{~Hz}$

(Single circuit line $300 \mathrm{~km}$ )

$r_{l}=0.06445, x_{u}=0.6095, b_{\mathrm{el}}=0.1776$

Infinite bus voltage $=1.0 \angle 0$

$x_{t h}=x_{t r}=0.13636, x_{d}^{\prime}=0.4245$

STATCON data

Base:300 MVA, $400 \mathrm{kV}, 12$ pulse

$r=0.01, x_{1}=0.15, b_{c}=1.136, R_{p}=78.7$ 